\title{
ARTICLES
}

\section{FROM INTERNATIONAL TREATIES \\ TO INTERNET NORMS: \\ THE EVOLUTION OF INTERNATIONAL TRADEMARK \\ DISPUTES IN THE INTERNET AGE}

\author{
MARCELOHALPERN ${ }^{*}$ \& AJAYK. MEHROTRA**
}

\section{INTRODUCTION}

In today's dynamic, digital economy, there is a global clash between geographically bounded trademarks and the limitless reach of the Internet. Trademark law, by definition, is premised on the principle of territoriality. The legal rights that give trademarks and other forms of intellectual property economic value are circumscribed by geography. The Internet, in contrast, knows no bounds. It is a vast and expanding international network of interconnected computers that is limited neither by space nor time.

Traditionally, discrepancies in international trademark rights have been resolved through international treaties. Countries exercising their national sovereignty have participated in time-consuming multilateral state-to-state negotiations, with global harmonization as the primary goal. Until recently, this conventional treaty approach has been successful in developing a sense of global comity among the signatories of various international agreements.

With the recent, incredible explosion of e-commerce, however, such a traditional process has become economically obsolete. The Internet's ability to provide information with unprecedented speed and efficiency has turned many traditional modes of human interac-

- Partner, Gordon \& Glickson LLC.

*" Staff Attorney, Gordon \& Glickson LIC Copyright 2000, Gordon \& Glickson ILC. Both authors would like to thank Lynn Stram for her assistance with this article. All translations have been verified by the authors and not by the Unizersity of Pensylizania Joumal of International Economic L ares 
tion- legal and otherwise-into relics of bygone days. The conventional process of harmonizing international differences in intellectual propenty law is no different. In place of the traditional process, a new approach towards international intellectual property is fast emergingone that rests not on treaties between multiple nation-states, but on a type of "Internet Common Law" that privileges the private contracts of individuals and the social norms of the cyberspace community. ${ }^{1}$

The development of an Internet Common Law has been accelerated in the area of domain name disputes. As the functional addresses of websites, domain names are a vital aspect of the stability and growth of the Internet and e-commerce. This stability and growth has been challenged recently by the conflicts between domain names and trademarks. One type of conflict has been created by "cybersquatters"- those who register domain names ahead of trademark owners in the hope of securing a quick profit. The cybersquatters benefit by negotiating to sell the rights to the domain name to the trademark owner. Another more difficult set of conflicts comes from competing but valid claims to trademarks that are used as domain names. The international system established to resolve these conflicts- the Uniform Domain Name Dispute Resolution Policy ("UDNDRP" or "ICANN Policy") adopted by the Internet Corporation for Assigned Names and Numbers ("ICANN")- is a prime example of how the conventional method of multinational cooperation is being supplanted by the new approach of individual consent and Internet norms.

This Article explores how this new approach of private ordering and Internet norms operates in the arena of international trademark disputes. The Internet, and the new economy it has spawned, has collided with traditional notions of trademark law. Section 2 of this Article surveys the wreckage of international trademark law that has been left in the wake of this collision. This Section begins with a brief background on the fundamentals of trademark law and the operation of the domain name system. It then explores how the domain name system, and the e-commerce it supports, have undermined traditional notions of international trademark law. Section 3 of this Article examines how the Internet Common Law has developed thus far and how it may be well suited, in spirit, to guide the resolution of interna-

1 Legal theorists, most notably Lawrence Lessig, have discussed how common law principles operate in cyberspace communities. See Lawrence Lessig, The Path of Giberlare 104 YALE L.J. 1743 (1995). The present Article, however, suggests that the Internet community has done more than borrow venerable common law principles; the Internet has inculcated its own crude form of the common law. 
tional trademark and domain name disputes. ICANN and its dispute resolution policy have in many ways come to embody important aspects of this Internet Common Law. By analyzing the origins, key elements, and limitations of this new international dispute resolution policy, Section 4 investigates how the ICANN Policy adheres to, and how it departs from, the spirit of the Internet Common Law. Using the ICANN Policy as a case study, this Article contends that international trademarks are only one aspect of a growing trend-fostered by the Internet-away from top-down administration and towards a more democratic, and perhaps even populist, mode of decisionmaking.

2. THE INTERNATIONAL TRADEMARK WRECKAGE:

WHEN THE INTERNET COLLIDED WITH INTERNATIONAL TRADEMARK LAW

\subsection{Trademark Basics}

Throughout the world, trademarks have two primary functions. First, they act as a signal to consumers, alerting them to the origins or manufacture of specific goods. ${ }^{2}$ When consumers come to associate a known mark with goods or services from a particular source, they usually rely upon the mark as a signal of the quality of such goods and services. ${ }^{3}$ Thus, trademarks are an essential part of developing a consumer brand. Second, trademarks are important in protecting the goodwill or consumer reputation of a company. A trademark is how a company identifies itself to potential customers. By investing resources in its products and its mark, a company has a vested interest in ensuring that consumers associate their mark with their quality goods and services. Likewise, trademark owners want to make sure that consumers are not deceived into purchasing inferior products that may have a mark that is confusingly similar to their own. Trademark owners, in other words, want to prevent competitors from "free riding" on the coattails of their efforts. Similarly, trademark owners do not want inferior competing products to diminish or "dilute" the

2 See J. THOMAS MCCARTHY, MCCARTHY ON TRADEMARKS AND UNFAIR COMPETITION $\$ 2: 6$ (4th ed. 1997) [hereinafter MCCARTHY].

3 For the purposes of simplicity, this Article will use the terms "trademarks" and "marks" synonymously to refer to both service marks and trademarks.

4 See MCCARTHY, supra note 2, $\$ 2: 15$. 
value of their products by altering the positive consumer image that is associated with their mark ${ }^{5}$

As identifiers of the source of commercial goods and services, trademarks are necessarily industry-specific and geographically limited. In other words, trademark protection exists to prevent confusion over the origins of particular products or services in a specific commercial area. So long as there is no "likelihood of confusion," companies using the same mark can, and do, generally operate at the same time in different industries or locations." The "United" mark is a textbook example of the industry-specific nature of trademark law. Both United Van Lines and United Airlines have exclusive rights to their respective marks, but because they offer different services, they coexist without infringing upon each other's intellectual property rights. Similarly, two companies that operate in the same line of business, but cater to distinct and separate consumer markets, could have similar marks, as long as the disparate locations of their markets could ensure that there would be no confusion over the origins of their respective goods and services.?

\subsection{The Domain Name System}

Trademarks have played an important role throughout the history of commerce, but the Internet's domain name system and the ecommerce that has mushroomed around it have made trademarks even more important. The domain name system is, in short, the indexing method that defines each of the networks and computers that make up the Internet. Computers connected to the Internet, and the websites that are located on specific computer servers, are identified by an unwieldy set of Internet protocol numbers that are often difficult to remember. Domain names function as a type of mnemonic, or alias, that assists Internet users in finding particular websites. Domain names are also a key element of the Uniform Resource Locators ("URL") needed to reach computers on the Internet. ${ }^{8}$ The University of Pennsylvania's home page, for example, is identified by the following set of Internet protocol numbers: 128.91.2.28. However, it is

5 William M Ladnes \& Richard A. Posner, The Economics of Trademark Lare 78 TRADEMARK REP. 267 (1988).

6 See MCCARTHY, supra note 2, IS 26:1-4, 29:1-7.

7 Hanover Star Milling Co. v. Metcalf, 240 U.S. 403, 414-15 (1916).

8 For more on how the domain name system works, see generally ELLEN RONY \& PETER RONY, THE DOMAIN NAME HANDBOOK 1-136 (1998), explaining the process of domain name registration as well as the system's benefits and drawbacks. 
much easier for an Internet user to remember that the domain name upenn.edu will allow him or her to connect to the University's computer. Plainly put, "a domain name is the simplest way of locating a website."

With the emergence of e-commerce, domain names have come to be much more than mere Internet addresses. They have become the new trademarks for a new economy. ${ }^{10}$ Consumers have come to rely upon domain names in much the same way as they rely on trademarks in the tangible world; domain names are seen as symbols that identify the source of particular products and services. Indeed, because the Internet has so pervaded our current ways of communicating, it is not unreasonable for an Internet user to associate a website or an e-mail address that contains a tangible world trademark with the owner of that mark. When a computer user types in a specific URL or sends an e-mail to an address that contains a well-known mark, the user reasonably believes that she is accessing information provided by the trademark owner or is communicating with the authorized agents of the trademark owner.

Domain names differ, however, from traditional trademarks in at least one highly significant way. Whereas traditional marks can coexist at the same time in multiple locales or lines of business, domain names cannot. Only one specific domain name can exist for each toplevel domain. ${ }^{11}$ For example, only one unique domain name can claim the commercially lucrative .com suffix for its Internet address. While in the tangible world United Airlines and United Van Lines can coexist peacefully, in cyberspace only one of these businesses can claim united.com. The scarcity of domain names, along with the first-come, first-serve policy of domain name registration, has done much to exacerbate the tensions between domain names and trademark law. ${ }^{12}$

9 Panavision Int'l, L.P. v. Toeppen, 141 F.3d 1316, 1319 (9th Cir. 1998).

10 See Susan Anthony, Domain Names: The New Trademarks, in TRADEMARK LAW \& THE INTERNET (Lisa E. Cristal \& Neal S. Greenfield eds., 1999).

11 Technically, a top-level domain is identified by the last group of two or three letters in an Internet address. Currently, there is a limited set of generic top-level domains that include .edu, com, and .org, among others. Top-level domain names also include country identifiers such as .fr for France and .uk for the United Kingdom. ICANN is presently considering expanding the range of top-level domains. See Carlos Grande, Nere Web Addresses May Be Launched Next Year, FIN. TiMES, July 17,2000 , at 3 (explaining that regulators voted for new Internet domain suffixes for the first time in a decade).

12 For more on how the first-come, first-serve domain name registration policy has affected trademark law, see Jessica Litman, The DNS Wars: Traderarks and the Intemet Domain Name Sjstem, 4 J. SMALI \& EMERGING BUS. L. 149 (2000). 


\subsection{The Territoriality Tradition of Intemational Trademark Law}

The conflict between domain names and trademark law has also turned on the issue of territoriality. While domain names- as the new trademarks-may serve some of the same purposes as traditional trademarks, they do not operate under the same established principle of territoriality. International law has had a long tradition of protecting trademark rights in accordance with the territoriality doctrine. ${ }^{13}$ Long before the Internet, trademark protection was an essential part of international trade. Globalization, despite being the shibboleth of today's academic and business communities, is not a new phenomenon. Goods and services have been exchanged across national boundaries for centuries, and trademark protection has been, for the most part, a universal concept with deep historical roots. ${ }^{14}$

Throughout this history, international trademark law has been defined by geography. Intellectual property rights have been recognized and enforced only within those nation-states that have clearly defined the scope of their intellectual property protection. Worldwide trademarks do not exist; therefore, trademark owners cannot restrict the use of their marks by others outside the borders of their home jurisdiction. Instead, trademark holders must ensure that their marks qualify for protection under the domestic laws of the foreign jurisdictions in which they plan to use their marks. ${ }^{15}$ To coordinate the different nation-state legal regimes, international organizations such as the World Intellectual Property Organization ("WIPO") have admin-

13 See generally Doris Estelle Long, The Territorial Nature of Intellectual Property Rights, in INTERNATIONAL INTELLECTUAL PROPERTY LAW 373, 374 (Anthony D'Amato \& Doris Estelle Long eds., 1997) (explaining the classical view of intellectual property rights, according to which "the authority of a country granting intellectual property protection can only extend to its borders," and the impact of that view on the business of authors and inventors of protected works in foreign countries) [hereinafter D'Amato \& Long].

14 See MCCARTHY, supra note 2, \ 2-6, at 2-11 (describing how all developed cultures and economic systems have trademark protection policies). The chief treaty governing international trademark law, the Nice Agreement Concerning the International Classification of Goods and Services for the Purposes of the Registration of Marks, commonly referred to as the Paris Convention, was signed in the late nineteenth century. See Paris Convention for the Protection of Industrial Property, Mar. 20, 1883, U.S.T. 1629. The Paris Convention was promulgated in 1883, adopted by the United States in 1887, and implemented in the United States through domestic legislation in 1903. See Michael V. LiRocchi et al., Trademanks and Internet Domain Names in the Digital Millernitum 4 UCLA J. INT'L I. \& FOREIGN AFF. 377, 410 (1999/2000).

15 Se MCCARTHY, supra note 2, $\$ 29: 1$, at 29-4 (explaining that a trademark has an individual legal existence under the laws of each country). 
istered a variety of treaties designed to harmonize a minimum level of international intellectual property protection. Many of these treaties obligate their signatories to extend national treatment to residents of other states. National treatment ensures a level playing field by requiring treaty adherents to grant an identical level of trademark protection for both foreign and domestic owners. Thus, a U.S. trademark holder can usually receive protection in a foreign jurisdiction, if she complies with that jurisdiction's trademark protection requirements and if the United States and the foreign jurisdiction recognize mutual rights through some sort of international agreement. ${ }^{16}$

\subsection{The Digital Challenge for the Treaty Regime of International Law}

The Internet has broken down many of the geographical and temporal premises of international law. As a communication tool, the new technology has radically accelerated the speed and ease with which individuals and institutions communicate with each other. This has led to unprecedented gains in economic efficiency. Similarly, ecommerce has revolutionized business models and practices. These efficiency gains and new business paradigms have caused the current state of international trademark law to become, at the very least, inconsistent and at worst, incoherent.

\subsubsection{Economic Efficiency}

The communication revolution wrought by the new technology has rendered the time-consuming process of negotiating multinational accords economically inefficient. The high transaction costs that accompany multilateral, and even bilateral, negotiations necessarily imply that reaching a mutually acceptable agreement will require a great deal of time and effort. The negotiations surrounding the North American Free Trade Agreement and the Uruguay Round of the General Agreement on Tariffs and Trade ("GATT") demonstrate that brokering international agreements is an expensive and arduous process- one that is frequently hampered by conflicting cultural nuances. ${ }^{17}$ While harmonizing international regulatory differences is still an admirable goal, the Internet has fostered a communication revolution-

16 See D'Amato \& Long, supra note 13, at 373 (providing that protection in foreign jurisdictions is dependent on whether the inventor is "subject to patent protection and upon the scope of rights the domestic law grant[s] to a patent owner").

17 See Finallys the Trade Agreement, WASH POST, Dec. 16, 1993, at A24; see also LiRocchi et al., supra note 14, at 410 (stating that international accord requires looking at cultural nuances and harmony of laws). 
complete with its own sense of decentralized, self-regulation-that seems at odds with the multilateral treaty approach. On one level, the Internet's effect on communication has made all forms of negotiations, including those between nation-states, quicker, easier, and more direct.

More importantly, the Internet has altered the relationship between individuals and their nation-states. With the Internet's ease of direct and continuous contact, individual citizens have come to rely less on their representative governments and more on coordinated private action to address even large-scale problems. ${ }^{18}$ Avoiding the bureaucracy of state action, Internet users have organized their own self-help methods through newsgroups, e-mails, and chat-rooms. These populist efforts toward self-regulation have required fewer resources and have often led to more effective solutions. In fact, ICANNs Domain Name Dispute Resolution Policy embodies much of this self-regulatory spirit of the Internet.

This does not mean to suggest, however, that international treaties in general are no longer necessary. They still play a fundamental role in opening markets and establishing international free-trade principles. Moreover, while e-commerce is certainly a portent of the future, it currently only makes up a small portion of international trade. ${ }^{19}$ Nevertheless, in the specific area of trademark and domain name disputes, the notion of relying on international accords to settle global discrepancies is an outmoded idea that does not correspond with the dynamic and swift nature of today's technology.

\subsubsection{The NewBusiness Models of E-Commerce}

International trademark law has also been challenged by the emergence of new e-business practices and models. Current international trademark treaties and case law are premised on an antiquated business model, which assumes that separate geographical markets are

${ }_{18}$ The recent recall of Bridgestone/Firestone tires is a prime example of how citizens throughout the world have used the Internet to share information and address problems that have traditionally been handled by government agencies. Se Karen Lundgaard, The Intemet Is Playing a Principal Role in Recall of Bridgestone/Firestone Tire, WALL ST. J., Aug. 16, 2000, at 14.

19 See UN Report Urges Developing Countries to Captune E-Commerce Boom AGFRP, Feb. 16, 2000, arailable at 2000 WL 2734305 (predicting the value of online transactions for this year to be approximately $\$ 377$ billion dollars). 
distinct areas of commerce. ${ }^{20}$ For example, the Paris Conventionthe principal treaty governing the international treatment of trademarks - is founded on the notion that companies looking to expand into new consumer markets must spend a great deal of effort and resources in researching and then ultimately penetrating these new markets. Ratified in 1883, the Paris Convention is oblivious to the alacrity and pervasiveness of e-commerce. The treaty, for instance, requires member states to recognize unregistered foreign marks when the foreign mark is well known, not necessarily in the state of origin, but in the locale where protection is sought. ${ }^{21}$ This provision not only fails to contemplate the global reach of e-commerce, which has the potential to make nearly all markets local in nature, but more importantly, this local knowledge requirement does little to avert potential domain name disputes. Under this provision, a potential cybersquatter could register a relatively unknown foreign trademark as a domain name and possibly suffer no consequences. The local knowledge requirement and other aspects of the Paris Convention demonstrate how the traditional trademark regime is clearly ill-equipped to deal with the problems of the twenty-first century.

\subsection{International Treaties and Caselawe}

More recent international agreements also have done little to address the conflict between domain names and trademark law. In the last few decades, GATT has sought to establish international norms for intellectual property agreements. As the name suggests, GATT was initially conceived as an accord to enhance international commerce by reducing tariffs and other trade barriers. During the Uruguay Round of GATT in the mid-1980s and early 1990s, however, the Agreement on Trade-Related Aspects of Intellectual Property Rights ("TRIPS") was established. 22 In many ways, the basic principles of TRIPS parallel what is already contained in the Paris Convention. In the context of trademarks and domain names, however, TRIPS provides added protection to trademark owners by broadening the notion

20 This logic also explains why trademark protection has historically been limited to the geographic area in which the mark owner conducts his or her commercial activity.

21 Paris Convention for the Protection of Industrial Property, Mar. 20, 1883, 21 U.S.T. 1629, stpra note 14, art. 4(A)(1).

22 Agreement on Trade-Related Aspects of Intellectual Property Rights, Dec. 15, 1993, Annex 1C, LEGAL INSTRUMENTS-RESULTS OF THE URUGUAY ROUND, 33 I.L.M. 81, 85 (1994) [hereinafter 'TRIPS Agreement]. 
of goodwill and by presuming that confusion is likely when a mark is used for identical goods and services. ${ }^{23}$ Nevertheless, because TRIPS was negotiated and instituted well before the development of ecommerce, the potentially abusive practice of cybersquatting is not addressed directly.

By contrast, the European Community's First Council Directive (the "Directive") seems to have anticipated the problem of cybersquatting, though it takes only a limited step in tackling the issue. ${ }^{24}$ The Directive explicitly allows members to deny registration for "bad faith," if the mark is used abroad. However, "bad faith" is only a necessary condition. The Directive requires that registration be denied only when both "bad faith" and a "likelihood of confusion" exist. ${ }^{25}$ Of course, in the context of domain name disputes, when the originator's mark is not well known in the European Union there is little chance of confusion. Thus, despite the Directive, a cybersquatter could be free to appropriate a foreign mark as part of a domain name.

Although international case law dealing with domain names and trademarks has been more flexible and responsive than the laws codified in treaties, it has developed gradually and unevenly, proving that there is indeed a need for a more stable, efficient, and transparent system for resolving international disputes. In an emblematic case concerning conflicting, yet valid, rights to a trademark used in a domain name, a U.K. court ruled that the first party to register and use the trademark in the domain name was legally entitled to use the mark as long as there was no likelihood of consumer confusion. ${ }^{26}$ In that case, a U.S. manufacturer of sports equipment, the Prince Sports Group, Inc., attempted to enjoin Prince plc, a British information technology ("IT") company, from using the prince.com domain name. The U.S. sporting goods manufacturer had valid trademark registrations for "prince" in both the United States and the United Kingdom, and the British IT company also had valid common-law rights in the United Kingdom to use the same "prince" mark. Prior to the Internet, the two companies, with their two distinct products and services, coexisted peacefully. However, when the U.S. sporting goods company sought to register prince.com as a domain name, it was surprised to learn that the U.K. IT company had already registered the domain

23 Id. art. 16(C); see also LiRocchi et al., supra note 14, at 389 (demonstrating that TRIPS is one of the international agreements relevant to trademark issues).

24 Council Directive 89/104/EEG, 1989 O.J. (L40) 1.

25 See id. art. 4(3).

26 Prince ple v. Prince Sports Group Inc., 1998 FLEET ST. REP. 21 (Ch. 1997). 
names prince.com and prince.co.uk. The U.S. company sent a ceaseand-desist letter threatening further legal action if the U.K. company did not transfer the domain name to the U.S. company. In response, the U.K. company brought an action for declaratory relief in London's High Court and deposited the domain names with the U.K. Court pending final decision. Relying on the theory of "first-in-time," the U.K. Court ruled in favor of the U.K. company. The court reasoned, first, that since domain names are registered on a first-come, firstserve basis, the U.K. company was the first organization to officially establish its valid trademark as a domain name. Second, and more importantly, the court reasoned that because the businesses of the two parties clearly were distinct, there was no likelihood of confusion.

In the context of explicit cybersquatting, most international courts, like U.S. courts, have rebuked attempts to extort trademark owners' rights. Courts in the Netherlands, for instance, not only have ruled against typical cybersquatters, they also have acknowledged that domain names within the top level of .com carry greater commercial value than other domain names. ${ }^{27}$ In Labouchere w IMG Holland, a Dutch court ruled that cybersquatters could be liable for trademark infringement even if the trademarks at issue could still be registered in a domain name other than .com. The court reasoned that consumers would still be confused by the squatters' .com website-even if it contained limited disclaimers.

These cases and others like it point to a growing trend among international and domestic courts. This trend discourages cybersquatting and supports the theory of first-in-time for those with valid but competing trademark claims. This tendency also shows how case law, because of its flexibility, is superior to treaties in dealing with the dynamic issue of domain name disputes. Like international treaties, however, international case law is jurisdiction-specific; it too is bound by geography. In this sense, regulation of domain name disputes requires a new approach that corresponds with the communication speed and economic efficiency of the Internet itself. ICANN's Uniform Domain Name Dispute Resolution Policy is a valiant first effort toward such a new approach. Despite its merits, ICANN's Policy is not without its limitations. Both the virtues and the drawbacks of ICANNs Policy can be judged in light of how well the Policy corresponds to the Internet Common Law that has helped give it life.

27 Labourchere v. IMG Holland, President District Court, Amsterdam, May 15, 1997 RvdW 193. 


\section{THE INTERNET COMMON LAW:}

A NEW APPROACHFOR A NEW ECONOMY

Like the judge-made common law that has guided AngloAmerican jurisprudence for centuries, the Internet Common Law is a flexible regime of rules and regulations that is based mainly on Internet custom and common usage. In the last few years, there has been a robust debate among legal scholars and practitioners about how law functions on the Internet. The idea of an Internet Common Law fits squarely within this debate. On one side of the dispute are those who argue that because the Internet is such a novel and revolutionary technology, it requires a radical paradigm shift in legal analysis. ${ }^{28}$ Others contend that, while the Internet is certainly a new technology, it still adheres to familiar legal concepts. ${ }^{29}$ This Article argues that, in the specific context of international trademark and domain name disputes, the Internet should be approached and respected as a unique place with its own set of social norms and community standards. Complete self-regulation, however, is not the solution. This Article takes the normative position that, on the contrary, international trademark and domain name disputes should be governed by a quasipublic institution that respects the Internet norms of private contracts and populist authority.

\subsection{Intemet Norm: Prizate Contracts and Populist A uthority}

The social norms and community standards that guide the Internet Common Law are not metaphysical ideals handed down by some Supreme Being. Rather, they are socially-constructed values that have evolved gradually over time, like other conventions embedded in a culture's social relations. One of the strongest social norms that has emerged is a reliance on decentralized private ordering. The Internet is, first and foremost, a dynamic technology. To keep pace with the dizzying escalation of technological change, Internet users have yearned for a flexible way to channel social behavior. There is perhaps no better way to inculcate flexibility into a rule-making system

28 Among the many authors who have argued that the Internet calls for a dra. matic change in legal principles, two of the most notable are David Post and David Johnson. See David R Johnson \& David Post, Law and Bonders-The Rise of Law in Gjerspace, 48 STAN. L. REV. 1367 (1996).

29 At the extreme end of this position are scholars who argue that there is no such thing as cyberspace law. See Frank H. Easterbrook, Giberspace and the Law of the Horse, 1996 U. CHI. LEGAL F. 207 (1996). 
than to allow affected parties to engage in their own contractual arrangements.

\subsubsection{Prizate Contracts}

Indeed, private contracts have become one of the hallmarks of the Internet. From the contracts we sign with our Internet Service Providers ("ISPs"), to the shrink-wrapped licenses we agree to when purchasing software, to the privacy policies we consent to when visiting our favorite websites, private ordering has become the dominant form of modern social relations. The metaphor of contracts is part of our everyday culture on and offline, but on the Web, agreements between consenting private parties have taken on added meaning. Unlike in the tangible world, where contracts are usually the culmination of face-to-face relations, agreements in cyberspace are often the only nexus between distant and anonymous parties. We may not personally know the online retailer from whom we purchase our books, flowers, and toys. However, by exchanging our credit card numbers for their goods and services, we are constantly engaging in a set of overlapping private agreements-agreements that govern such varied issues as the confidentiality of the information we provide and the guarantee that our goods will arrive on time. As e-commerce has come to dominate our consciousness-if not our buying habits-this reliance on decentralized economic and legal decision-making has become a common feature of Internet behavior.

This, of course, does not mean that there is no place for more centralized institutional support in the development of Internet standards. Cyberspace is not the political theorist's "state of nature." The private ordering that has come to dominate the Internet is premised on the underlying support of the state and other quasi-public institutions, such as ICANN. Government agencies responsible for consumer protection, for example, still play an essential role in defining and enforcing the default rules of all businesses, including ecommerce. To have any meaning, contracts- whether they are made in atomic space or cyberspace-must rely upon these background rules.

30 The "state of nature," a hypothetical scenario conjured by seventeenth century philosopher Thomas Hobbes, imagined what life was like before any government was created. See Alain De Botton, The Arts: Who's in Charge?, DAILY TEL., June 28,1997 , at 12 . 


\subsubsection{Populist Authority}

While these default rules are important for the private contracting aspect of Internet norms, the appeal to judicial or legislative authority is generally not part of the Internet culture. Rather, the Internet community often turns to grass-roots, extra-legal self-help methods to resolve online issues. By coordinating individual Internet users on a large-scale basis, consumer advocates have been able to circumvent many established legal institutions in favor of a more bottom-up type of activism. A reliance on populist forms of authority, or what may be called "peer pressure with a stick," has thus emerged as another type of Internet norm.

There may be no better example of such online populist authority than the evolution of website privacy policies. In the early stages of ecommerce, many websites did not provide detailed information regarding how they would subsequently use the personal data gathered from their visitors and customers. Indeed, privacy policies themselves were quite rare during the early days of e-commerce. However, when certain sites violated the trust of their visitors, other leading sites developed privacy policies as a competitive, commercial advantage. It was not long before Internet users came to expect some sense of privacy and confidentiality in the information that they provided. As a result, online privacy policies soon lost their function as a competitive edge and became a cost of entry for any new site. The new Internet norm became quite clear: no privacy policy means no visitors and no advertisers.

A similar type of populist authority emerged when website operators transgressed well-established expectations of privacy and confidentiality. Consider, for example, how Internet users reacted to a potential change in privacy policies at America Online ("AOL"). In the summer of 1997, AOL, the dominant international ISP, notified its approximately 8.5 million customers that it was planning to alter a provision in the company's service agreement. Apparently, AOL had recently become aware of the lucrative potential of sharing with other marketing companies the personal information that AOL gathered from its users. AOL wanted to change the terms of its service agreement so that it could reveal certain user information to interested business entities. AOL users did not take the possible change in policy lightly. A bottom-up response to this unilateral corporate decision began to percolate, as the media, AOL chat groups, and community bulletin boards circulated the news. Within hours after the news of the possible change had surfaced, AOL was deluged with a virtual 
avalanche of consumer protest e-mails and telephone calls. In a matter of days, the company was forced to reverse its position. ${ }^{31}$

Even outside the realm of online privacy, populist authority on the Internet has been exercised with dramatic force. For several years, self-appointed administrators of Internet newsgroups have been issuing Usenet "Death Penalt[ies]" against unresponsive ISPs. ${ }^{32}$ Since at least 1997, individual users of Internet newsgroups have been working together in a loose coalition to regulate abusive postings to newsgroups. In an effort to curb unsolicited newsgroup postings, commonly known as "spam," these self-appointed regulators cancel abusive messages and block postings that originate from indifferent ISPs. ${ }^{33}$

Technically, any member of a newsgroup or electronic bulletin board can cancel or delete spam. However, issuing a Death Penalty, which promises to block all further postings from a specific ISP, is a much harsher penalty that usually requires some consensus within the newsgroup community. Indeed, newsgroup users have developed general guidelines as to what constitutes spam and what can be done to halt it. Generally, when spam from a particular ISP begins to flood a newsgroup, members will notify the ISP of the problem. It is only when the ISP does not respond to the community outcry that the Usenet Death Penalty is issued as a last resort.

For example, in December of 1999, a group of Usenet participants proposed a Usenet Death Penalty against Excite@Home when the participants determined that a large amount of spam was originating from Excite@Home servers. The California-based ISP was only able to avert the capital punishment when it reconfigured its internal architecture to filter such postings and assured the Usenet community that it would take steps to educate its members. ${ }^{34}$ Excite@Home is just one of many ISPs that has been forced to implement antispamming measures as a response to Usenet Death Penalties.

The peer pressure that has come to represent the Internet Common Law also played a role in resolving at least one trademark and

31 Rajiv Chandrasekaran, $A$ OL Cancels Plan for Telemarketings: Disdooure of Members' Numbers Protested, WASH. POST, July 25, 1997, at G1.

32 Corey Grice \& Jim Hu, Excite@Home Usenet Death Penalty Lifted, CNET News, at http://news.cnet.com/ news/0-1004-200-1526165.html (Jan. 18, 2000) (defining the term Usenet Death Penalty).

33 Id.

34 Id. (describing the methods used by Excite@Home to avert a Usenet Death Penalty). 
domain name dispute. In a conflict between a U.S. online toy store with the domain name etoys.com and a European site for digital artists with the domain name etoy.com, Internet community pressure was instrumental in resolving the dispute. In September 1999, the online retailer, eToys.com, filed a trademark infringement and unfair competition lawsuit against the registrants of etoy.com, after customers of the toy store, who had mistakenly visited the artistic website, complained about the provocative nature of some of the digital art displays. Although the Swiss-based art site had registered its etoy domain name in 1995, two years before the online toy store got its domain name, a California Superior Court issued a preliminary injunction against etoy, shutting down the artists' website. Though the toy seller had registered its trademark first, etoy claimed that it had a right to the mark as a result of its earlier use of the mark in commerce. Soon after the injunction was issued, and well before the case was resolved, a huge groundswell of online protest against the publiclytraded e-commerce toy seller ensued. Angry e-mails were fired off to the Santa Monica, California headquarters of eToys.com; several antieToys websites were established, criticizing the toy retailer for its corporate bullying; community chat rooms became clogged with protest messages that rallied more support for the artists; and cyberspace sitins were staged, as Internet users flooded the eToys.com site with bogus orders. The artists themselves filed their own lawsuit and launched a site at toywar.com to protest what they viewed as the reverse domain name hijacking of their website. ${ }^{35}$

Within a few months, the toy seller responded to Internet community pressure by negotiating a settlement with the conceptual artists. Initially, the e-commerce company, which was valued at approximately $\$ 6$ billion at the time, ${ }^{36}$ attempted to buy out the artists' domain name rights. ${ }^{37}$ When that measure failed, the toy seller sought a settlement that would give them limited control over the content of the iconoclastic art site. After the artists rejected such censorship, the two parties eventually reached an agreement whereby both sides

${ }^{35}$ Richard Leiby, ETos rs. Etog $A$ Clash of Commerce and Art, WASH POST, Dec. 10,1999 , at E1.

36 Id

37 See Patricia Jacobus, eToys Seeks Settlement in Dispute reith etoy, CNET News, (Dec. 29, 1999), at http://news.cnet.com/news/0-1007-200-1509522.html (last visited Sept. 26, 2000). 
dropped their respective lawsuits, and the toy seller agreed to pay the art group's legal fees and other related expenses. ${ }^{38}$

The etoy victory vividly illustrates how Internet users have harnessed the power of new technology to challenge even large-scale commercial interests. Indeed, by connecting like-minded users, ${ }^{39}$ the Internet has empowered individuals in nearly every aspect of their lives. As consumers, Web surfers have become much more than passive receivers, or abstract demographic targets, of mass-market advertisers. With power in numbers, Internet consumers have forced the market to acquiesce to their demands, especially with regard to their privacy concerns.

Similarly, as employees, intranet ${ }^{40}$ users have broken down much of the hierarchy of the conventional corporation. The sullen days of Whyte's "Organization Man"41 have been replaced by today's euphoric moments of knowledge sharing. The top-down corporate memo has been supplanted by the bottom-up intranet. Precisely because the Internet and intranets connect people to each other and empower them through these connections, the pace and quality of human discourse has radically changed. This greater flow of knowledge has decreased the friction between private parties, allowing for greater private contracting. At the same time, it has also challenged the bureaucratic hierarchy that has for so long subjugated consumers and employees. In sum, the new technology and the Internet Common Law it has fostered have rejuvenated individual choice and democratic decision-making. ${ }^{42}$

Yet, if private contracts and populist authority are two of the central norms embodied in the Internet Common Law, the question remains: why is the Internet Common Law, and not some other method of regulation, best suited to address the issue of international trademark and domain name disputes? In determining trademark

38 See Patricia Jacobus, eTos Settles Net Name Dispute rith etoy, CNET News, (Tan. 25, 2000), at http://news.cnet.com/news/0-1007-200-1531854.html (last visited Sept. 26, 2000).

39 It may be more accurate to state that the Internet has helped create the likeminded, as well as bring the already like-minded folks together.

40 An intranet is a network of self-contained computers that are usually delimited within an organization. MICHAEL D. SCOTT, INTERNET AND TECHNOLOGY LAW DESK REFERENCE 279 (1999).

41 WILIIAM H. WHYTE, JR., THE ORGANIZATIONMAN (1972).

42 See generally RICK LEVINE ET AL., THE CIUETRAIN MANIFESTO: THE END OF BUSINESS AS USUAL (2000) (discussing the Internet and its impact on the modern world). 
rights on the Internet, why should deference be given to private contracts and populist authority?

In some ways, the Internet Common Law is not particularly well suited to govern trademark and domain name disputes. The eToys example may, in this case, be the exception rather than the rule. The Internet Common Law works best in those areas where novel issues arise from the everyday operations of e-commerce. Online privacy policies are the best example of how private contracts and coordinated consumer pressure can shape the rules and regulations of cyberspace. One reason why the Internet Common Law has been so effective in the context of online consumer rights may be that e-commerce has developed sui generis, in the absence of direct government regulation. Website privacy policies were not mandated by any government agency, but rather developed indigenously over time as a response to individual consumer concerns. In contrast, the government has been involved in trademark law and domain name registration from the beginning of the Internet. The state has had a significant role in managing how domain names are assigned and in policing trademark violations. Thus, there has been less opportunity for individual decisionmaking and group pressure.

The limited number of domain names is another reason why the Internet Common Law does not function as effectively in resolving trademark and domain name conflicts. Online consumer rights are furthered by individual decisions and group pressure, which are not limited by any such constraint. E-commerce exists to satisfy the needs and desires of consumers. Thus, individual consumers can withhold their consent to website agreements and appeal to populist authority to force Internet companies to meet their demands. The preservation of online privacy policies, for example, is not usually accomplished through zero-sum solutions. Consumer demands for privacy can be met without significantly harming website owners.

By contrast, domain names are limited to the generic top-level domains that currently exist. In a conflict between two valid and competing rights to a .com address, only one party can prevail. Either United Van Lines or United Airlines, but not both, will be able to claim united.com as its domain name. ${ }^{43}$ The company that obtains rights to such a URL necessarily benefits at the expense of the other legitimate trademark holder. Unlike consumer rights, trademark and

43 Indeed, United Airlines has registered the domain name united.com as its Internet address. 
domain name disputes are very much a zero-sum game-one side gains while the other loses.

The scarcity of top-level domain names and the significant government regulation of trademarks and the domain name system illustrate the limits of the Internet Common Law. Nevertheless, the spirit of the Internet Common Law cannot be ignored, even in the context of international trademarks and domain names. Indeed, as the eToys controversy demonstrates, online populist authority is a force to be reckoned with. Any stable, efficient, and long-lasting solution to the tension between trademarks and domain names will need to acknowledge the power of individual consent and populist authority. That is why the Internet Common Law should be viewed not as an air-tight system of rules and regulations but as an approximate guide for how trademark and domain name disputes should be handled.

\subsection{The Intemet Common Lawand International Trademark and Domain Name Disputes}

There are at least two main reasons why a solution to trademark and domain name disputes should correspond to the Internet Common Law. These reasons are based on the principles of (1) flexibility and certainty, and (2) functionality. First, a dynamic, evolving technology requires a system of governance that is both flexible and predictable. Second, because the Internet functions mainly as a relatively easy-to-use communication device- albeit an unprecedented one- it calls for a legal regime that operates on a similarly intuitive level of human communication.

\subsubsection{Flexibility and Certainty}

It is important to remember that the Internet is not a monolithic technology, but rather a network of layered applications. ${ }^{44}$ For most computer users, the Internet comes in various manifestations, from email to newsgroups to the World Wide Web. Many of these applications have developed over time, as the Internet itself has evolved. Several years ago, not even the most prescient of technology experts could have predicted that the Internet would rise from such humble military and academic roots to create the current e-commerce innova-

44 See Timothy Wu, Application-Centered Intemet A nalysis, 85 VA. L. REV. 1163, 1164 (1999) (explaining further that legally important issues concerning the Internet do not stem from basic Internet protocols; rather, they are a function of the particular application). 
tions. In order for such a dynamic technology to continue to develop, it must remain relatively free from static and confining sets of rules and regulations.

The need for a flexible system of rules is not, however, unique to the Internet. All laws struggle with the conflicting needs for flexibility and certainty. On the one hand, the law requires detailed and specific rules that address particular contexts in order to insure that like cases will have like outcomes. ${ }^{45}$ On the other hand, the law seeks to avoid a cumbersome multiplicity of different rules for different situations, so that it is malleable and general enough to apply to a variety of situations. This general tension in legal theory between flexibility and predictability is even more pronounced in the context of Internet governance because computer technology is such a dynamic phenomenon. The Internet's vitality has led many legal commentators to argue that flexibility should trump certainty and predictability in the context of online legal issues. For these scholars, the solution to Internet-related legal problems lies not with legislatures and judges, but with the individuals who are the direct participants in the cyberspace community. Analogizing to the medieval Law Merchant, some commentators have argued that the first step in addressing an Internet legal issue should be to do nothing, to allow the cyber-participants to work out their own problems, with their own customary solutions. ${ }^{46}$

Such a laissez-faire approach, however, ignores the social aspects of cyberspace, and belies the network of comected computers that is the Internet. There are no entirely self-engaging acts on the Internet or otherwise. Certainly, private contracts are more flexible than statutes or judicial precedents, but they do not account for the adverse effects on third parties, what economists call negative externalities or "external diseconomies." deed come to mutually agreed upon positions- if they can overcome

45 The need for predictability has been a defining aspect of law for many legal theorists. As Holmes wrote over a century ago, "The prophecies of what the courts will do in fact, and nothing more pretentious, are what I mean by the law." Oliver Wendell Holmes, The Path of the Lares 10 HARV. L. REV. 457, 461 (1897). For a more recent analysis of the need for predictability in the law, see Frederick Schauer, Prediction and Particularity, 78 B.U. L. REV. 773 (1998).

46 Trotter Hardy, The Proper Legal Regime for "GJberspace", 55 U. PITT. L. REV. 993, 1019-21 (1994) (comparing the development of customs governing transactions in cyberspace to the Law Merchant, a set of customary practices which became a practical, flexible, and expedient means of resolving disputes between merchants that functioned independently of other bodies of law).

47 Paul Samulson, ECONOMICS 477 (10th ed. 1976). 
the transaction costs of bargaining-but such agreements will give little solace to parties who are adversely affected by, and not privy to, the private contracts. Moreover, the Internet is, in many ways, still in its infancy. Like other innovative technologies before it, the Internet and e-commerce will continue to need stable and reliable regulations to grow. ${ }^{48}$ Privileging flexibility over predictability may, ultimately, do more harm than good for this growing technology.

For international trademark and domain name disputes, concern for adverse third party effects and the future of e-commerce makes pure self-regulation an even less viable option. Despite the early explosive growth of e-commerce, companies and consumers alike are still experimenting with the full effects of purchasing online. The potential of e-commerce remains untapped. To ensure that companies will be adequately rewarded for their investments, and that consumers will remain satisfied with their online buying experiences, trademark law must be predictable. It is unlikely that private contracts, without any further institutional regulation, can guarantee such predictability. Similarly, for e-commerce to flourish, it is essential that consumers have trust and confidence in online retailers. Private agreements about how trademarks will be used in domain names will need to be sensitive to such consumer needs. Trademarks, of course, exist to assist consumers in their buying decisions, and in this regard private parties have an incentive to insure that the proper signal is given. But it is also possible that consumer interests will not be the first priority of private companies negotiating an agreement over trademark rights. To ensure that consumers will be protected from confusion over trademarks and domain names, some sort of overarching authority is necessary. In the end, the fate of e-commerce will rest on the careful balance between the differing interests of consumer protection and property rights.

The Internet, therefore, cannot be left only to the individual interests of private parties; it is too important a part of our social culture to allow it to be a quasi-laboratory for the Coase theorem. ${ }^{49}$ Instead, cyberspace legal issues, such as domain name disputes, should be ad-

48 Throughout American legal history, law has played an instrumental role in guiding new technology and fostering economic expansion during formative eras. See generally MORTON HORWIT, THE TRANSFORMATION OF AMERICAN LAW, 17801860 (1977) (studying the relationship between private law and economic change in the nineteenth century); J. WILLARD HURST, LAW AND ECONOMIC GROWTH: THE LEGAL HISTORY OF THE LUMBER INDUSTRY IN WISCONSIN, 1836-1915 (1964) (chronicling the role of regulators in the rise of the Wisconsin lumber industry).

49 See Ronald H. Coase, The Problem of Social Cost, 3 J.L. \& ECON. 1 (1960). 
dressed by some type of intermediate authority that respects the vitality of the Internet and the flexibility of private contracts and is at the same time sensitive to effects on the community and the need for certainty. The Internet Common Law is a flexible yet predictable regime attuned to the needs of the community; therefore, some form of intermediate authority that has a basis in the Internet Common Law may be the best solution to many of the novel legal issues of cyberspace, including the international dispute over trademarks and domain names.

\subsubsection{Functionality}

The functional aspects of domain names are a second reason why some form of the Internet Common Law should govern trademark and domain name disputes. Domain names make up the backbone of the Internet. As website identifiers, they are heuristic devices that appeal to human intuition. The Internet, however, was not always organized by domain names. Back in its earliest stages of development, when it was known simply as the ARPANET, computers connected to the network were identified only by their Internet Protocol addresses, the long string of numbers that facilitated contact between computers. Not until Jon Postel, one of the early technical architects of the Internet, and his colleagues at the University of California, assigned "nicknames" for these Internet Protocol addresses, did domain names come into being. The early domains were created primarily to help direct communication traffic. Separate computers administered each domain, and the "root server" directed traffic among the domains. ${ }^{50}$

As the Internet developed beyond its military and academic roots, domain names took on greater importance. Today, not only are they the trademarks of a new economy, but they are also cultural icons. From billion dollar initial public offerings, to incessant online and offline marketing of websites, to routine inclusion of hyperlinks in our everyday e-mails, a dot-com mentality has pervaded our cultural consciousness. Domain names have assumed this added economic, social, and cultural significance precisely because they are intuitive. Common sense Internet usage has developed to the point where many people reasonably assume that a well-known trademark is represented by a .com location: one has come to reason that if something exists in

50 See Joseph P. Liu, Legitimacy and Authority in Intemet Coondination: A Domain Name Case Studb, 74 IND. L.J. 587, 591 (1999). 
the tangible world, it must exist in cyberspace as well. Thus, in a highly consumer-conscious culture, such as our own, we can expect individuals to believe that the trademarks and images ingrained in their minds are in fact connected with the websites that contain these marks.

A technology so indebted to human intuition calls for a legal system that is equally as grounded in common sense. For many nonexperts, however, the law is a rarefied world of technical processes and esoteric terminology. Whether it is the appellate process or recently enacted legislation, many of the particulars of law remain far removed from the everyday thinking of ordinary people and typical Internet users. Sociolegal research on the U.S. system of litigation has demonstrated that those who benefit most from the law are not "oneshotters" or individual litigants but rather institutional "repeat players" who have the human and financial capital to navigate through the legal system's complicated channels. ${ }^{51}$

In contrast, the Internet Common Iaw is based on common sense customs and usage. The appeal to populist authority is a vivid illustration of how formal legal procedures have been surpassed by more customary forms of consumer pressure, so too is the paramount concern for online privacy. Although established forms of authority, such as government agencies, have at times intervened on behalf of private Internet users, the online right to privacy developed organically into what is now a cherished cyberspace custom. Internet users have presently come to expect that the personal information they provide to websites will remain private and confidential, regardless of the financial future of the sites.

Similarly, the Internet community has developed its own set of rules regarding online courtesy, commonly known as "netiquette." As a method of maintaining social order, netiquette does not govern online communication through any centralized enforcement mecha-

51 See Marc Galanter, Why the "Hazes" Come out A bead: Speculations on the Limits of Legal Change, 9 LAW \& SOC'Y REV. 95, 97 (1974) (discussing that the structure of the American legal system can be used to effect redistributive change).

52 Several failed e-commerce companies recently caught the attention of consumer advocacy groups and the Federal Trade Commission when they sold customer data in contradiction of their privacy policies. See generally Greg Sandoval, Failed Dot-Com May Be Selling Your Prizate Information, CNET News, at http://news. cnet.com/news/0-1007-200-2176430.html (June 29, 2000) (reporting on three financially troubled companies that have sold or are trying to sell customer information).

53 VIRGINIA SHEA, NETIQUETTE 20 (Seth Ross ed., Albian Books 1994). 
nism- in other words, there is no netiquette police. Rather, netiquette, like ordinary etiquette, functions as a form of underlying cultural control. Members of a cyberspace community adhere to these unwritten rules because they play a critical role in keeping communications stable, fair, and frictionless. For example, netiquette's discouragement of "flame wars" - a series of angry e-mails or group postings exchanged between members of an online newsgroup or community-helps maintain the camaraderie and mutual respect of discussion groups. Although occasional "flames," or angry postings, are tolerated (and sometimes even encouraged), all-out "flame rears" are viewed as egotistical and boring displays of immaturity that are ultimately nothing more than "an unfair monopolization of bandwith." 54 Netiquette, the development of a grass-roots authority, and the passion for online privacy are all examples of how the Internet has evolved pragmatically to develop indigenous responses to functional issues.

This pragmatic aspect of the Internet, evidenced by its willingness to allow for the development of internal, functional customs, is perhaps the main reason why some institutional derivation of Internet Common Law would be best suited to handle trademark and domain name disputes. Any solution to the international problem of trademark and domain name disputes must be cognizant of the intuitive nature of the Internet. International treaties with subtle legal points cannot satisfy the common sense functionalism of the Internet, nor can they appeal intuitively across cultural borders. Likewise, judicial decisions, based on the diverse legal processes of different jurisdictions, can only resolve momentary tensions of conflicts. Judges cannot provide large-scale, cosmopolitan solutions needed to keep the Internet and e-commerce moving along at their current exponential rate of growth. Instead, another medium is necessary to resolve the tensions in trademark and domain names disputes; a third way between international accords and judicial decisions that will insure the intuitive and structural integrity of the Internet is required. The ICANN Policy is in many ways an example of such a third way.

\section{ICANNS UNIFORM DOMAIN NAME DISPUTE RESOLUTIONPOLICY: A CASE STUDY}

As an institution, ICANN has its roots in the diverse communities that make up the Internet. Created in 1998, at the prodding of the

54 Id. at 43. 
U.S. Department of Commerce, ICANN consists of a broad coalition of business leaders, technical advisers, academics, and other Internet users. While the organization's responsibilities remain rather general, one of its primary duties has been "to coordinate the technical management of the Internet's domain name system." ${ }^{35}$ To further this goal, ICANN has implemented one of its most significant policy achievements: the Uniform Domain Name Dispute Resolution Policy (the "Policy"). ${ }^{56}$ However, before one can objectively analyze the effectiveness of the Policy- that is, whether or not it adheres to the underlying principles of Internet Common Law- one must first understand how the Policy came into being.

\subsection{Policy Origins}

The origins of ICANNs Policy are in many ways a culmination of several earlier attempts to address the proper administration of the domain name system. From the 1998 U.S. Green Paper ${ }^{57}$ that spurred the need for ICANN, to the institutional support provided by the World Intellectual Property Organization ("WIPO"), the ICANN Policy has evolved from a government policy statement to one of the most significant institutional achievements of the Internet.

Prior to ICANN, the domain name registration process was administered by only one company, Network Solutions Inc. ("NSI"), a private U.S. corporation based in Herndon, Virginia. In 1992, as part of a cooperative agreement with the U.S. National Science Foundation, NSI was given a monopoly on domain name registration. ${ }^{58}$ As the entity solely responsible for administering generic top-level domain names, NSI quickly became embroiled in conflicts over domain name and trademark rights. ${ }^{59}$ In response, from 1995 through 1998, NSI issued several versions of its domain name resolution policy. According to these policies, NSI would place on "hold" those domain

55 ICANN Fact Sheet, at http://www.icann.org/general/fact-sheet.htm (last modified Mar. 25, 2000).

56 ICANN Uniform Domain Name Dispute Resolution Policy, at http://www. icann.org/udrp/udrp-policy-24oct99.htm (implementation documents approved Oct. 24, 1999).

57 Improvement of Technical Management of Internet Names and Addresses, 63 Fed. Reg. 8826 (proposed Feb. 20, 1998) (to be codified at 15 CF.R. pt. 23) [hereinafter Green Paper].

58 G. Peter Albert, Jr., Eminent Domain Names: The Struggle to Gain Control of the Intemet Domain Name System 16 J. COMPUTER \& INFO. L. 781 (1998).

59 See Dan Goodin, NSI's Liability in Trademark Disputes Reduced, CNET News, (Apr. 29, 1999), at http://news.cnet.com/news/0-1005-200-341869.html. 
names under issue, until a court of competent jurisdiction handed down a decision. ${ }^{60}$ In defense of its policies, NSI argued that it was remaining neutral by freezing controversial domain names until the parties resolved their differences through conventional litigation.

In reality, however, NSI's policy of placing domain names on hold did not satisfy either trademark holders or domain name owners. ${ }^{61}$ Trademark holders complained that because NSI suspended only those domain names that were identical to registered marks, confusingly similar domain names remained exempt. Domain name holders were equally displeased. They argued that NSI's policy extended trademark rights beyond those accorded to mark holders in the tangible world. Domain name holders contended that NSI's policy would harm those companies that used domain names for businesses that bore no resemblance to the registered trademark use. ${ }^{62}$

In response to these and other criticisms, the Clinton administration issued a policy statement in 1998 to re-evaluate the Internet domain name system. ${ }^{63}$ This initial draft did not contain a policy to resolve domain name and trademark disputes, but a subsequent and more comprehensive statement, dubbed the White Paper, was issued soon thereafter.

\subsubsection{U.S. White Paper}

In June 1998, the U.S. Department of Commerce issued the Clinton administration's revised domain name policy statement, commonly known as the White Paper. ${ }^{64}$ Essentially, the White Paper called for privatization of the management of Internet names and addresses. To facilitate increased global participation and competition, the White Paper suggested that it was time for a new, private, nonprofit organization, independent of the U.S. Government, to organize and administer the domain name system. ${ }^{65}$ The increased conflicts between trademarks and domain names and the need for new top-

60 Albert, supra note 58 , at 794.

61 See id. at 795.

62 Luke A Walker, Note, ICANN's Uniform Domain Name Dispute Resdution Pdicy, 15 BERKELEY TECH. L.J. 289, 296 (2000).

63 Green Paper, supra note 57.

64 NAT'L TELECOMM. AND INFO. ADMIN., DEP'T OF COMMERCE, 63 Fed. Reg. 31,741 (proposed June 10, 1998) [hereinafter White Paper].

65 Id. 31,749-51. In addition to managing IP addresses and root servers, the White Paper called for the new organization to monitor protocol parameters and to increase the number of top-level domains. Id. 
level domain names were two specific issues that the White Paper cited as reasons for a new domain name policy. ${ }^{66}$

Unlike the policy proposal that preceded it, the White Paper was well received by the international Internet community because it adhered to the spirit of the Internet Common Law. For example, the White Paper explicitly outlined four guiding principles for the new system of domain name management: (1) stability; (2) competition; (3) private, bottom-up coordination; and (4) representation. ${ }^{67}$ Each of these principles reflected important aspects of Internet norms and culture. The recognition of private, bottom-up coordination is particularly significant since it is this appeal to populist authority that most resembles the flexibility and dynamism of the Internet Common Law. In the words of the White Paper, a "private coordinating process is likely to be more flexible than government and to move rapidly enough to meet the changing needs of the Internet and of Internet users. The private process should, as far as possible, reflect the bottomup governance that has characterized development of the Internet to date." ${ }^{\prime 68}$

In a less explicit manner, the White Paper also recognized the importance of private contracts for the Internet community. In regard to trademark issues, the White Paper made several recommendations as to how trademark and domain name disputes should be handled. One of the most important recommendations was to use the registration contract as a method to bind parties to alternative dispute resolution procedures. The White Paper specifically recommended that the new organization adopt policies whereby "[d]omain name registrants would agree, at the time of registration or renewal, that in cases involving cyberpiracy or cybersquatting (as opposed to conflicts between legitimate competing rights holders), they would submit to and be bound by alternative dispute resolution systems ... for the purpose of resolving those conflicts." 69

It has been this acknowledgment of private contracts and bottomup governance that has given the White Paper such significant influence over the development of ICANN and its Uniform Domain Name Dispute Resolution Policy. Indeed, members of the Clinton administration as well as denizens of the international Internet com-
66 See id. 31,742 .
67 Id $31,749$.
68 Id.
69 Id 31,750 . 
munity hailed the White Paper as an example of Internet consensus building. ${ }^{70}$ This so-called Internet consensus could not, however, have been transformed into institutional reality without the assistance of some traditional international organization. The White Paper suggested that the government would "[a]sk WIPO to convene an international process including individuals from the private sector and government to develop a set of recommendations for trademark/domain name dispute resolutions...."11 WIPO responded to this request by developing the backbone of what would become ICANNs Policy.

\subsubsection{The Creation of ICANN and the 1999 WIPO Final Report}

In response to the White Paper recommendations, a group of Internet associations came together in the late summer of 1998 to form the new, private, non-profit corporation that would manage the Internet domain name system. ${ }^{72}$ That new corporation was ICANN. At first, it was unclear what ICANN's responsibilities entailed. Conferences were convened throughout the world, prior to the establishment of ICANN, to discuss what the future of this new quasi-public institution would be. Several issues were discussed at these international conferences including board and membership composition, Internet security and privacy, and the development of a new domain name dispute resolution system. ${ }^{73}$

In the end, the institutional structure of ICANN corresponds to many aspects of the Internet's established norms and customs. ${ }^{74}$ It is ICANN's Policy, however, that resonates most with the Internet Common Law. Adapted from a WIPO proposal, the ICANN Policy

70 See Dezelopments in the Law The Law of Gberspace, 112 HARV. L. REV. 1577, 1669-70 (1999) [hereinafter Dezlopments]. However, the White Paper was not without its critics. See generally Alyssa Katz, Stars Spar ouer U.S. Net Pdicy, Wired News, (June 11, 1998) (reporting criticism of the White Paper by Harvard Professor Lawrence Lessig), at http://www.wired.com/news/politics/0,1283,12931,00.html.

71 White Paper, supra note 64, at 31,751.

72 For a more detailed account of the formation of ICANN, see generally Dezelopments, supra note 70, at 1671-76 (describing ICANN's structure and purpose).

73 Id at 1672.

74 ICANN's bylaws display how the corporation is bound by transparent measure of decision-making, as policies and decisions by the board are required to be posted on the Internet and are open to external comments. See BYLAWS FOR INTERNET CORPORATION OF ASSIGNED NAMES AND NUMBERS, art. III, at http:// www.icann.org/general/bylaws.htm (last modified July 16, 2000). 
was approved and implemented in the fall of $1999 .^{75}$ The WIPO proposal was first prepared in response to the White Paper's request that WIPO be involved in the development of an alternative dispute resolution system. As one of the sixteen specialized agencies of the United Nations system of organizations, WIPO is an intergovernmental organization that is responsible for promoting the protection of intellectual property rights throughout the world. ${ }^{76}$ WIPO operates under the traditional paradigm of state-to-state cooperation in the administration of multilateral treaties. It is thus highly ironic that this intergovernmental organization is responsible for forging an alternative dispute resolution system that in many ways undermines the authority of the same nation-states it is supposed to be coordinating.

From July 1998 to April 1999, WIPO undertook an extensive international consultation process (WIPO's First Internet Domain Name Process) that resulted in a Final Report containing recommendations regarding trademark and domain name disputes. ${ }^{77}$ Taking its cue from the White Paper, the WIPO Final Repoit called for an explicitly minimalist approach in addressing trademark and domain name conflicts. Specifically, the Final Report recommended that ICANN adopt a uniform dispute resolution policy that is limited in scope "to cases of bad faith, abusive registration of domain names that violate trademark rights...."78 Procedurally, the Final Report recommended that ICANNs Policy be conducted online and that final determinations be limited to orders canceling or transferring domain name registrations and allocating costs of the procedure against the losing party. The Final Report also made recommendations regarding exclusions for famous and well-known marks and for ICANN to expand the number of generic top-level domain names "in a slow

75 See Domain Name Resdution Serice for gLTDs, at http://arbiter. wipo.int/domains/gltd/index.html (last visited Sept. 12, 2000); see also Janet Kornblum, Domain Name A coond a Step Closer, CNET News, (Aug. 25, 1998) (discussing an earlier proposal to create an international nonprofit corporation made up of representatives from all parties interested in the domain naming process) at http://news.cnet.com/ news/0-1005-200-332578.html; Niall McKay, New Internet Government Forged, Wired, (Sept. 17, 1998) (explaining the problems arising from the creation of the ICANN Policy), at hitp://www.wired.com/news/politics/ $0,1283,14795,00 \cdot \mathrm{html}$.

76 WIPO, What Is WIPO, at http://www.wipo.org/eng/dgtext.htm (last visited Sept. 12, 2000).

7 See WIPO, Final Report of the WIPO Internet Domain Name Process, WIPO Pub. No. 92-805-0779-6, (Apr. 30, 1999), at http://wipo2.wipo.int/process1/report/final report.html.

78 Id 
and controlled manner."79 By November 1999, many of the recommendations contained in the WIPO Final Report were adopted by ICANN, including a system of best practices for registration authorities and an administrative system for resolving domain name and trademark disputes. ${ }^{80}$

WIPO's involvement with ICANN's Policy did not end with the Final Report. WIPO's Arbitration and Mediation Center-a forum established in 1994 to help reconcile international intellectual property disputes-soon became the locus for implementing ICANN's Policy. By December 1999, WIPO's Arbitration and Mediation Center began providing dispute resolution services to give effect to ICANNs Policy. ${ }^{81}$ One day after ICANN's Policy was implemented, the first trademark and domain name complaint was lodged with WIPO over worldwrestlingfederation.com. ${ }^{82}$ As of September 19, 2000, over 1800 complaints have been filed with WIPO regarding generic top-level domain names and 1099 cases have been decided or terminated. ${ }^{83}$

\subsection{Key Elements of ICANN's Policy}

The growing number of cybersquatting complaints filed with WIPO demonstrates how, in many ways, ICANN's Policy has appealed to the norms and customs of the Internet community. The administrative procedures underlying ICANN's Policy, the use of private contracts to implement the policy, and the enhanced efficiencies of the resolution process are all examples of how ICANN has properly respected the fundamental norms of Internet culture.

79 Id. The Final Report also recommended that improved registmation practices, such as collection of accurate and reliable contact information for domain name holders, be adopted by all registration authorities.

80 See ICANN, Timdine for the Formulation and Implementation of the Uniform Domain Name Dispute-Resdution Policy, at http://www.icann.org/udrp/udrp-schedule.htm (last visited Sept. 12, 2000).

81 See Domain Name Resdution Serrice for gL TDs, supra note 75.

82 See World Wrestling Fed'n Entm't, Inc. v. Bosman, WIPO Case No. D99. 0001 (Jan. 14, 1999), azailable at http://arbiter.wipo.int/domains/decisions/html /d99-0001.html.

83 See ICANN, Statistical Surrmany of Procesdines Under Uniform Dispute Resdution Policy, (Sept. 28, 2000) at http://www.icann.org/udrp/proceedings-stat.htm. WIPO has also recently begun to provide mediation services for country code top-level domain names. See WIPO, Dot Country Codes Tum to WIPO for Help in Resoling Gjersquatting Disputes, at http://arbiter.wipo.int/press/update106.html (last visited Sept. 28, 2000). 


\subsubsection{Administratize Procederres}

Unlike the NSI dispute resolution policies, ICANN's Policy does not hastily place a hold on domain names that are under dispute. Rather, ICANN's Policy provides for a more balanced and flexible set of administrative procedures. When a trademark owner files a complaint with WIPO, or any of the other ICANN-approved dispute resolution service providers, ${ }^{84}$ ICANN Policy requires WIPO to review the complaint for compliance purposes and then forward the complaint to the appropriate domain name holder. After receipt of the complaint, the domain name holder has twenty days to file a response. Once WIPO has received the domain name holder's reply, an administrative panel of either one or three persons is convened. ${ }^{85}$ The administrative panel will have fourteen days to analyze the case and provide a decision to WIPO, at which time WIPO will notify both parties and publish the full decision on a publicly available website. ${ }^{86}$ Ideally, the entire resolution is designed to cost approximately $\$ 1500$ to $\$ 3000$ and take less than fifty days to complete. ${ }^{87}$ After the decision has been handed down, either party is free to dispute the administrative panel's decision in a conventional court of appropriate jurisdiction. ${ }^{88}$ Meanwhile, ICANN will refrain from implementing the panel's decision until a judicial decision has been rendered.

84 WIPO is not the only international organization that has been approved by ICANN to implement the UDNDRP. The other approved providers for the Uniform Domain Name Dispute Resolution Policy are the National Arbitration Forum, Disputes.org/eResolution Consortium, and the CPR Institute for Dispute Resolution. See ICANN, APPROVED PROVIDERS FOR UNIFORM DOMAIN NAME DISPUTE RESOLUIION POLICY, at http://www.icann.org/udrp/approved-providers.htm (last modified May 21, 2000).

${ }_{85}$ The administrative panel will consist of a single panelist, unless either party to the dispute requests a three-member panel. ICANN, RULES FOR UNIFORM DOMAIN NAME DISPUTE RESOLUTION POLICY, at http://www.icann.org/udrp/ udrp-rules-240ct99. htm, at 6(b)-(e) (last visited Sept. 14, 2000).

${ }_{86}$ Id. at 15(b), 16(a)-(b).

87 WIPO Guide to the Uniform Domain Name Dispute Resdution Policy, at http://arbiter.wipo.int/domains/guide/index.html, Overview of the Administrative Procedure (last visited Sept. 13, 2000).

$88 \mathrm{It}$ is still unclear how conventional judicial bodies will view the administrative decision rendered under ICANNs Policy. At least one U.S. federal court has stated that courts are not bound by the administrative proceedings, although the court did suggest that some degree of deference may be granted to these panel decisions. See Weber-Stephen Prods. Co. v. Armitage Hardware \& Bldg. Supply Inc., 54 U.S.P.Q. 2d BNA 1766 (N.D. Ill. 2000); see also Victoria Slind-Flor, Count Cumbs Power of ICANN, NAT'L L.J., May 22, 2000, at B6 (reporting that courts are "not bound by the administrative proceedings of the organization established to provide management of the Internet domain-name system"). 
The ICANN Policy works best in those areas where it corresponds with the underlying principles of the Internet Common Law. For example, by limiting the dispute resolution process to the trademark owner and the domain name holder, and removing the registrar from the conflict, ICANN Policy supports the Internet's emphasis on flexibility. Prior to the ICANN Policy, NSI found itself embroiled in litigation that hindered its ability to continue to register domain names and provide a predictable and stable environment for the growth of ecommerce. ICANNs Policy is a more even-handed attempt to balance the rights of trademark owners and domain name holders. Whereas NSI would presume trademark infringement and place on hold the domain names involved in trademark litigation, ICANNs Policy takes the more prudent step of refraining from changing the status of domain names while expediting the resolution process. Finally, by providing registrars with best-practices guidelines on obtaining accurate registration information, the ICANN Policy also provides the stability and predictability necessary for the continued growth of the Internet.

\subsubsection{Registrants' Mandatory Consent to A rbitration}

In addition to providing increased flexibility and predictability, ICANN's Policy also reinforces the Internet's reliance on private contracting. The ICANN Policy has been adopted by all accredited domain name registrars for those domain names ending in .com, .net, .org, and a select few country-code top-level domains. ${ }^{89}$ ICANN's Policy is automatically integrated into the domain name registration agreements offered by these registrars. ${ }^{90}$ Thus, when one seeks to register a domain name with one of these accredited registrars, that person consents to abide by ICANN's administrative dispute resolution system as part of her registration agreement. This mandatory consent to arbitration uses the Internet's penchant for private contracting to insure stability in the ICANN dispute resolution process. All who want to participate in the mainstream of Internet association must agree to participate in the administrative dispute resolution process, while still retaining the right to take their dispute through conventional litigation channels. The mandatory consent to administra-

89 Se ICANN, UNIFORM DOMAIN NAME DISPUTE RESOLUTION POLICY, at http://www. icann.org/udrp/udrp-policy-24oct99.htm, Notes 2 (last visited Sept. 14, 2000) [hereinafter ICANN POLICY].

90 See id Notes 3. 
tive proceedings also eliminates the registrar from any legal liability and allows the dispute resolution process, as well as Internet growth, to progress unabated.

\subsubsection{Increased Efficiency}

In contrast to conventional litigation, ICANNs Policy is perhaps best suited for Internet culture because it places a premium on monetary and time efficiency. The Internet is a dynamic technology that is rapidly changing to meet the demands and needs of the cyberspace community. As such, it requires a general and uniform process of dispute resolution that can cultivate rather than hinder such change. By decreasing transaction costs, and increasing resolution speed, ICANN's Policy provides dynamic technology with a dynamic dispute resolution process. Rather than tying up trademark and domain name conflicts in protracted legal proceedings, ICANN's Policy offers an alternative that is significantly less expensive for both parties and leads to a quicker result. Consider, for instance, the first complaint filed under the ICANN Policy with WIPO. In that case, the World Wrestling Federation, with relatively little expense compared to conventional litigation costs, prevailed in having the domain name worldwrestlingfederation.com transferred to it within forty days of filing the complaint. Even the domain name holder, Michael Bosman, who was forced to hand over the domain name, agreed that ICANN's Policy was economically efficient and fair. ${ }^{91}$

The use of expert arbiters on administrative panels also makes ICANN's Policy more efficient. Unlike most civil courts, methods of alternative dispute resolution often rely on mediators that are well versed in the details of particular types of conflicts. ICANNs domain name dispute resolution system is no different. It relies on panelists that are not only familiar with arbitration and alternative dispute resolution, but have experience in the areas of intellectual property law, e-commerce, and the Internet. ${ }^{92}$ This added knowledge base suggests that, at the very least, parties to a domain name conflict can expect a proficient arbiter to be presiding over their grievances.

91 Jeri Clausing, Wrestling Group Wins Bade Use of Its Name on Intemat, N.Y. TIMES, Jan. 17, 2000, at CA.

92 See WIPO, WIPODomain Name Pandists, at http://arbiter.wipo.int/domains/ panel/index.html (last visited Sept. 13, 2000). 


\subsection{Limitations of ICANN's Policy}

While the ICANN Policy contains many elements that adhere to Internet culture, including respect for private contracts, the need for flexibility, and the appeal for efficiency, the policy also has its limitations. First, because the ICANN Policy takes a self-avowed minimalist approach towards trademark and domain name disputes, it does not address the more difficult issues beyond cybersquatting. Second, because ICANN's Policy deals only with trademarks that exist among the top-level domain name registrars, there are other types of intellectual property, and an entire swath of the Internet community, that remains unaffected by ICANN's Policy. Third, on an empirical level, ICANN's Policy seems to be reinforcing a bias towards large commercial interests, namely those who already have trademarks registered.

\subsubsection{Deals Only With A busize Registrations}

Since its origins in the U.S. White Paper and the WIPO Final Report, ICANN's Policy has remained wedded to taking a minimalist approach towards addressing the intersection of international intellectual property and the Internet. ICANN's Policy focuses solely on trademarks, to the exclusion of other intellectual property rights. It deals only with the issue of bad faith trademark abuse, or cybersquatting. Section four of ICANN's Policy explicitly states that three cumulative conditions must be met in order for a complaint to be filed. First, the domain name must be "identical or confusingly similar to a trademark... in which the complainant has rights." ${ }^{33}$ Second, the domain name holder must have "no rights or legitimate interests in respect of the domain name." ${ }^{94}$ Third, the domain name must have been registered and used in "bad faith." 95

The focus on cybersquatting is commendable. By specifically targeting cybersquatters, ICANNs Policy helps preserve the intuitive functionality of the Internet. E-commerce and Internet use rely primarily on the convenience of the World Wide Web. Hoarding domain names that are identical or similar to registered trademarks hinders such convenience and intuitiveness. Cybersquatting prevents trademark owners from exercising their intellectual property rights in a new medium and misdirects online consumers to alternative sites.

\footnotetext{
93 ICANN POLICY, supra note 89, at 4(a)(i).

94 Id. at 4(a)(ii).

95 Id. at 4(a)(iii).
} 
ICANNs Policy appropriately attacks such "bad faith" domain name registration. However, it does not deal with the more complex and troubling issue of legitimate competing trademark claims on the Internet. As the Internet and e-commerce continue to develop across international borders, the conflict between geographically bounded, legitimate trademark rights will continue to pose legal problems. If ICANN is to endure as an institution, it must address those problems that cannot be so easily dismissed.

\subsubsection{ICANN's Policy L imited to Registered Trademarks}

A second drawback of ICANNs Policy is its limited scope. Currently, ICANN's Policy has been designed to deal only with registered trademarks found in the most ubiquitous top-level domain namesthe lucrative .com, net, and .org domains. Cybersquatters, however, have moved beyond registered trademarks to stake out other forms of intellectual property on the Internet. Intellectual property, outside of registered trademarks, such as geographical indications, trade names, and personality rights associated with celebrity names, has become the latest fodder for cyberpiracy. ${ }^{96}$ ICANN has thus far been able to deal with some of these issues, particularly the cybersquatting of celebrity names, on an ad hoc basis. For example, a WIPO panel recently ordered the holder of the domain name juliaroberts.com to transfer the domain name to the American actress. ${ }^{97}$ If ICANN's Policy is to become a stable, uniform method of resolving domain name disputes, it must move beyond ad hoc solutions. This requires implementing a corollary to its policy that deals with those intellectual property rights outside of the traditional rubric of trademarks.

To their credit, ICANN and its supporting organizations, such as WIPO, have recognized some of the limitations of the ICANN Policy. Several member-states of WIPO, for example, have solicited WIPO to embark upon a second round of international consultations to address these unresolved issues, especially the protection of domain names that are not registered trademarks. In response, WIPO commenced the Second Internet Domain Name Process, a process identical to the

96 See John Hartje, Resduing Internet Domain Name Disputes, INTELL. PROP. TODAY, Aug. 2000, at 38.

97 See Charles Arthur, Julia Roberts Regains the Rights to Her Oren Domain INDEP. (London), June 3, 2000, at 5. 
first set of consultations that produced the WIPO Final Report. ${ }^{98}$ The organization is expected to issue a final report sometime in $2001 .^{99}$

\subsubsection{Bias Toueard Large Commercial Interests}

The third, and perhaps greatest, defect in ICANN's Policy is its partiality toward the large commercial interests that often initiate the domain name dispute resolution proceedings. As an empirical matter, $80 \%$ of the cases decided by WIPO's administrative panels have been in favor of the complainant. ${ }^{100}$ Furthermore, of the one thousand or so cases that have gone before all four of the ICANN-approved arbitration boards, $75 \%$ have been decided in favor of trademark holders. ${ }^{101}$ On the one hand, the overwhelming success of trademark owners can be viewed as a natural outcome of the ICANN Policy structure. Since only abusive registrations can be challenged, and because only trademark owners can initiate proceedings, it would appear natural that most hearings would be rather clear-cut decisions in favor of those with existing property rights.

Nevertheless, the bias toward trademark owners may have farreaching and unsettling repercussions. Indeed, in those areas where ICANN has attempted to move beyond or against the Internet culture, the quasi-public institution has come under fire from the Internet community itself. Critics of ICANN have claimed, for example, that the current structure of ICANNs Policy de-emphasizes free speech concerns in favor of commercial interests. ${ }^{102}$ Critics fear that ICANN's Policy may have a chilling effect on corporate criticism websites. Disgruntled consumers and other individuals have been using the Internet to voice their displeasure with some of the world's largest multinational corporations. ${ }^{103}$ Some technology experts worry

98 See WIPO to Probe New Issues Relating to Domain Name A buse, (July 10, 2000), at http://wipo2.wipo.int/process2/press/235.htm.

99 Id.

100 See Dot Country Codes Tum to WIPO for Help in Resoling Gbersquatting Disputes, (July 31, 2000), at http://arbiter.wipo.int/press/update106.htm.

101 See Laurie J. Flynn, Whose Name Is It Anzreans Arbirration Pands Fazoring Trademark Holders in Disputes ouer Web Names, N.Y. Times, Sept. 4, 2000, at C3 ("In the continuing battles between the owners of trademarks and individuals with Internet domain addresses identical to them or nearly so, the trademark owners appear to be far ahead.").

102 See id. (citing James Love, director of the Consumer Project on Technology, criticizing ICANNs Policy for being biased in favor of trademark holders).

103 See Carolyn Said, Dat-Complaints; Companies Leam the Hard Way that Critics are Taking Their Name in Vaim, S.F. CHRON., July 25, 2000, at A1 (detailing that numerous sites have arisen for the purpose of trashing well-known corporations). 
about whether ICANN's Policy favoritism may deter individuals from taking on such corporate power or whether it will give the multinational corporations the ability to acquire critical sites with relative ease and little expense.

Besides the criticism of ICANN's Policy, commentators have also been quick to assail ICANN's dilatory response to the call for expanding the number of top-level domain names. ICANN's predecessor, NSI, acknowledged the need to increase the number of top-level domain names. NSI appeared to be aware that the artificial scarcity of domain names created an unnecessary tyranny of the .com domains. Entangled in many of the early trademark and domain name disputes, NSI recognized that the tension between the multiple trademarks of the tangible world and the uniqueness of the com domain names could be resolved by creating new top-level domains. Proposals were circulated that would have relieved the pressures and demands for a .com domain name. With an expanded number of generic top-level domain names, multiple owners of identical marks could find suitable Internet addresses. United Airlines could use united.air, while United Van Lines could have rights to united.van. Both companies would have adequate online exposure and consumers would be properly guided to the company that offers the services they desire.

Despite the appeal of creating more domain name space, ICANN appeared at first to be persuaded by trademark owners who argued that increasing the number of domains would simply increase the possibility of consumer confusion. ${ }^{104}$ Yet, if likelihood of confusion is the proper litmus test for protecting trademarks, the idea of adding new domain names should clarify rather than confuse the primary functions of different companies and organizations. Will Internet users really be confused between ford.car and ford.foundation? ICANN initially seemed to agree that increasing domain names was a risky proposition. However, at its most recent meeting, the organization agreed to add approximately six new top-level domain names, but without clarifying how many names would be phased in or what the precise names would be. ${ }^{105}$

104 See generally INTA Response to the U.S. Gozermment Paper on the Improzement of Tedmical Management of Intemet Names and Addresses, at http://www.ntia.doc.gov/ ntiahome/domainname/130dftmail/scanned/INTA htm (stating that INTA, an organization devoted to trademark protection, believes that where a trademark is unlawfully used as a domain name, there will be increased consumer confusion about the source of the product or service offered on the Internet).

105 Associated Press, New Web Site Suffxes Approzed, (July 16, 2000), at http:// news.cnet.com/news/0-1005-200-2269908.html?tag=st.ne.1002.srchres.ni. 
In addition to increasing the number of top-level domain names, ICANN could also address its critics by correcting those aspects of its dispute resolution policy that are contrary to the standards of the Internet Common Law. ICANN's Policy could be reformed to include the democratic aspects of website communication. Populist authority, embodied in the varieties of online consumer protests, is one of the touchstones of the Internet Common Law. However, ICANNs Policy currently does little to protect individuals who use websites to parody or criticize trademark holders. Recall that ICANNs Policy requires that a complainant must demonstrate that the original domain name holder has "no rights or legitimate interests in respect of the domain name." 106 Without clarifying what constitutes a "legitimate interest," ICANNs Policy leaves individual Internet protesters vulnerable to the possibility of having their legitimately expressive domain names taken from them. To address this issue, ICANN could reform its Policy to specify that free speech qualifies as a legitimate interest in a domain name.

\section{CONCLUSION}

As a case study of the Internet Common Law, ICANN's Policy amply demonstrates how this quasi-public institution has struggled to correspond with the customs and norms of Internet culture. In those areas where ICANN's Policy meshes with the Internet Common Law, ICANN appears to be a success. When the ICANN Policy defers to the Internet community's desire for private contracts, as it does when it requires mandatory consent to arbitration through the registration process, ICANNs Policy is respected as a flexible and efficient method of dispute resolution. Likewise, when ICANN's Policy attempts to preserve the intuitive functionality of domain names by targeting cybersquatters, the policy is hailed as a success. On the other hand, when ICANN and its Policy try to do too much, such as when they take on the role of the United Nations for the Internet or when they appear to favor the commercial interests of trademark holders over the free expression of individuals, the new organization is scrutinized as an undemocratic and unrepresentative coalition of special interests.

For ICANN to endure as a lasting institution of Internet governance, it must come to recognize its connection to the Internet culture that has given it shape. ICANN has evolved as a byproduct of the

106 ICANN POLICY, supra note 89. 
collision between geographically bounded trademark law and the limitless reach of the Internet. This clash between the Internet and traditional notions of international trademark law has left a void-a void that has been filled by an organic yet crude system of rules and regulations that appeals to the private ordering and democratic decisionmaking of the Internet community. Supplanting the conventional methods of international dispute resolution, this new system of rules and regulations has eschewed the traditional process of multilateral treaty negotiations in favor of a more private bottom-up approach to resolving online intellectual property conflicts.

In searching for the appropriate system of governance, the Internet community has no need for an organization that seeks to control or dictate the pace of technological change. What cyberspace participants yearn for instead is an organization that will guide them easily and quickly through the growing pains of global Internet development. Even the present tension between trademarks and domain names may be a fleeting dilemma for such a sophisticated technological age. It is not unrealistic to speculate that new technology may one day resolve the conflict between domain names and trademarks once and for all. There are already technologies under development that would make it easier for an Internet user to find firms by their true names, regardless of their domain name, further reducing confusion between like-sounding domain names and diminishing the power of trademarks as domain names.

Until such technology is implemented, however, it is up to the Internet community to ensure that ICANN remains true to its roots and that this new quasi-public creation remains attuned to the needs of the community that it is meant to serve. For ultimately, ICANNs Policy is not just about containing the risks of cybersquatting, it is about developing an important, though perhaps transitory, institution that can govern the resolution of international trademark disputes in the Internet age. 
* * * * * * * 